\title{
Advances in discrete material handling system design
}

\author{
SRINIVASAN RAJAGOPALAN and SUNDERESH S HERAGU \\ Decision Sciences and Engineering Systems Department, Rensselaer Polytech- \\ nic Institute, Troy, NY 12180, USA \\ e-mail: [rajags,herags]@rpi.edu
}

\begin{abstract}
The paper presents an outline of the research done in the area of facility layout and discrete material handling system design. The objective of this paper is to observe the trend in the literature in the area of manufacturing system design and predict the direction of future research in this area. The paper attempts to link the areas of facility layout design and material flow network design. A methodology for solving the integrated design problem is presented. An algorithm which aids in solving the combined pick-up/drop-off point location and material handling flowpath problem is outlined.
\end{abstract}

Keywords. Facility layout; automated guided vehicles; material handling system; integrated system design.

\section{Introduction}

The key design aspects involved in a manufacturing company are product design and process design. Product and process design involve designing the product while taking into consideration the processes to be used to manufacture that product. Process design includes equipment selection, designing the machine layout and the material handling system. Two key aspects that influence the efficiency of a manufacturing setup are the facility layout and material handling system design and operation. This paper analyzes the trend in the literature pertaining to facility layout and discrete material handling systems and projects the direction of future research in this area.

\section{Facility layout design}

Depending on how the machines are laid out, a manufacturing system can be broadly classified as:

(a) Traditional manufacturing system;

(b) Cellular manufacturing system.

In a traditional manufacturing system, the machines are arranged within a given space to minimize the total material travel. The cellular manufacturing system is based on the 
concept that all machines that perform operations on parts with similar processing requirements can be classified and grouped into cells (Heragu 1994). A cellular manufacturing layout tries to minimize material handling costs between cells and also between the individual machines in a cell. The different methods available for solving the layout problem are the quadratic assignment problem (QAP) and its variations, graph theoretic approaches and meta-heuristics based on simulated annealing, genetic algorithms and tabu search. For a more detailed survey of the techniques available for modelling and solving the facility layout problem, the reader is referred to Kusiak \& Heragu (1987), Heragu \& Kusiak (1991), Heragu $(1992,1997)$ \& Hassan (1994).

The earliest formulation for the facility layout problem involved setting it up as a QAP. The objective function in this case was a quadratic function which calculates the total cost of transferring material between machines. The constraints for this model specify that each site is assigned to only one machine and that each machine can occupy only one site. This formulation includes binary variables which indicate whether or not a machine is assigned to a given site. The implicit assumptions in this model are that all the cells are of equal size and shape. The QAP is known to be NP-complete (Sahni and Gonzalez 1976). In the past, attempts to solve the QAP optimally have focussed on transforming it into an equivalent linear mixed integer model. The transformed model, which has a larger number of variables and constraints than the QAP, was then solved using branch and bound and cutting plane algorithms. These algorithms were good for solving problems involving a maximum of 10 to 15 facilities.

Exchange algorithms based on the 2-opt and 3-opt methods have also been used to solve the layout problem. These algorithms are based on the principle of exchanging the positions of 2 or 3 facilities and checking the effect of this exchange on the objective function. If an improvement in the objective function is found, then the new layout is selected. The drawback in these methods is that they do not consider all the possible layouts that exist in the solution space and therefore are sub-optimal algorithms. These algorithms need an initial starting point which can be any feasible solution. The quality of the final solution depends upon the initial solution. However, these methods allow the user to generate a few good layouts from which the final layout can be selected.

The shift in paradigm and focus on cellular manufacturing systems led to a focus on an additional area of research, namely machine grouping. The design problem is divided into two parts - (a) Grouping of machines into cells, and (b) layout of the cells. In order to generate an overall optimal layout, a solution approach which simultaneously determines the grouping of machines and the layout of the cells is desirable. However, due to the complexity in modelling and solving such a combined problem, most approaches attempt to solve the two problems sequentially. For a more detailed explanation and a literature review of the cellular manufacturing system layout problem, the reader is referred to Chen (1995).

\section{Material handling system design}

The material handling system (MHS) design, consists of determining the material handling system to be used, calculating the unit loads or batch size for the MHS and assigning specific 
material handling equipment to departmental moves and developing the flowpath for the system. The types of material handling devices to be used, are mainly dependent on the size of the company, the types of operations taking place and amount of space available in the factory floor. Smaller companies prefer to use more traditional material handling devices such as forklifts or trucks, sometimes in conjunction with pick and place robots. Assembly operations and line-balancing operations tend to use conveyors because they allow the workers to perform the necessary operations on the part while it moves from one station to another. Automated storage/retrieval systems (AS/RS) are used in warehousing operations. Industries that are involved in sorting and packaging type of operations tend to use palletizers and sortation conveyors. The current trend seen in large manufacturing companies is the employment of automated guided vehicles (AGVs) as material handling devices. AGVs are preprogrammed trucks that are controlled through a central computer. The AGVs go through a predetermined route and make stops at designated machines, where the material is either picked up or dropped off by other automated material transfer devices. Because AGVs are expected to be the dominant material handling device in future manufacturing systems, this paper focusses on the use of AGVs in the material handling function.

An AGV system comprises 3 parts, namely the vehicle, the guidance system and the control system. The vehicle in itself is a driverless unit with a built-in charging system, an on-board controller, a communication unit and a frame. The guidance system consists of a guidepath and a tracking system. The guidepath could be either a physical metal wire used for tracking (active tracking) or a wireless system which detects the vehicle based on optical or wireless metal detection techniques (passive tracking). The control system consists of the controller which brings together the vehicle and the tracking system. It acts as the brain for the entire system. The control system also takes upon the task of route selection, blocking and tracking loads. An AGV system has several advantages among which are reliability, automated operation, reduced material damage during transfer, ease of change in the layout and increased efficiency of the entire manufacturing system. It also offers the user real-time control of the material handling system and on-the-spot decisions such as change in routing or assignment of AGVs to specific moves. The main disadvantage of AGVs are their high cost. They also need polished floor surfaces and removal of obstacles in the flowpath before they can be put into operation.

A control classification scheme for an AGVS is presented by Peters et al (1995). A cubic classification structure that indicates the complexity of the problem based on guidepath determination, vehicle capacity and vehicle addressing mechanism is presented. Details of the levels and sublevels that partition an AGV system are also presented. This paper concentrates more on the control aspects of an AGV system. Sinreich (1996) and Heragu \& Rajagopalan (1996) discuss in detail the research done in the area of AGV flowpath design. Sinreich (1996) gives an overview of the design models that have been developed for discrete material flow systems. Heragu \& Rajagopalan (1996) present a classification scheme which can be used as a tool in identifying the various aspects involved in developing a flowpath for an AGV based system and also discuss the merits and demerits of all the models developed so far.

The classification scheme for the AGV flowpath design problem presented in Heragu \& Rajagopalan (1996) is based on: 
Type of flowpath - traditional, single loop, tandem layout, loop layout and terminal AGV flowpath;

Travel direction - unidirectional, bi-directional;

Solution techniques - mathematical programming models, rule based solutions, heuristic solution techniques, simulation methods, mixed approach (i.e. combined simulation and analytical approach);

Assumptions made - layout given, pick-up/drop-off points given;

Objective function - total loaded travel time, travel distance of loaded vehicles, total travel distance, maximum travel distance, total path distance, overall cost.

The main categories for classification are the type of flowpath assumed in the problem, the type of AGV flowpath design required - i.e., the travel direction of the AGVs, the solution techniques used to solve the models developed, the assumptions made while developing these models and the objective function used in them.

\section{AGV flowpath design}

Maxwell \& Muckstadt (1982) first identified the problem of AGV system design. They tackled the problem of identifying the number of AGVs required for a system assuming that the guidepath was already laid out. The first models developed to solve the layout problems were mathematical programming models which tried to minimize the total travel distance of loaded vehicles for a given layout. Branch and bound techniques were developed to

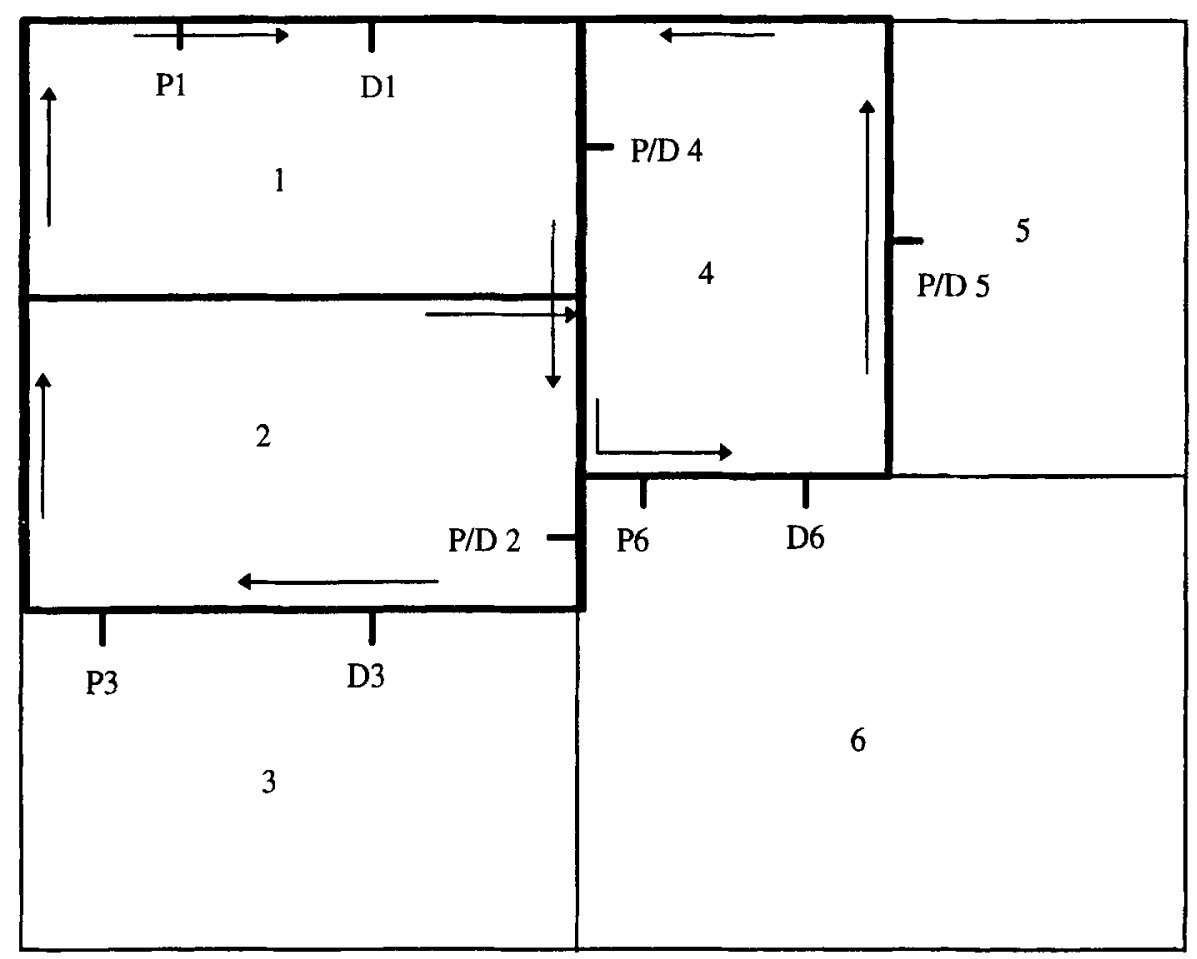

Figure 1. A schematic showing a traditional AGV flowpath design. 
solve these problems. The traditional flowpath problem was also modelled as a graph network and solved. Figure 1 shows a schematic of a traditional flowpath. A graph network considers the pick-up/drop-off points as nodes and the flowpaths as arcs. Pick-up/dropoff $(\mathrm{P} / \mathrm{D})$ points are those points in a machine or a cell where the material handling system loads or unloads the material required for that machine or cell. Later formulations tried to minimize the total loaded and unloaded travel time for a given AGV system. Network based approaches to solving the flowpath problem also include formulating it as a multicommodity flow problem. The solution methods to all these problems are mainly rule-based which are easy in solving small problems. Rule-based solutions are those which are specific to a problem and cannot be generalized. The rules generated simplify the problem under consideration and reduce the size of the solution space. However most of the approaches become impractical when solving large, real life problems (i.e. problems with more than 20 facilities). Kouvelis et al (1992) developed a set of heuristics to solve the AGV flowpath problem. They presented 5 different heuristic approaches to solve the unidirectional flowpath problem including a simulated annealing based approach. Usher et al (1988) presented a two-phase iterative heuristic to solve the unidirectional layout including the determination of $\mathrm{P} / \mathrm{D}$ points. The first phase develops a flowpath based on a simple model and in the second phase the $\mathrm{P} / \mathrm{D}$ points are determined based on minimizing the distance between any two stations using $m$ one-median problems.

The next development in AGV flowpath design came with the concept of an optimal single loop (figure 2). This concept developed by Tanchoco \& Sinreich (1992) is an alternative to the traditional flowpath design. An optimal single loop involves connecting all the $\mathrm{P} / \mathrm{D}$ points with the smallest possible single unidirectional loop. The simplicity of this concept eliminates problems such as collision, blocking, and other routing conflicts. This method tries to find the best single loop guidepath and locates the P/D points along

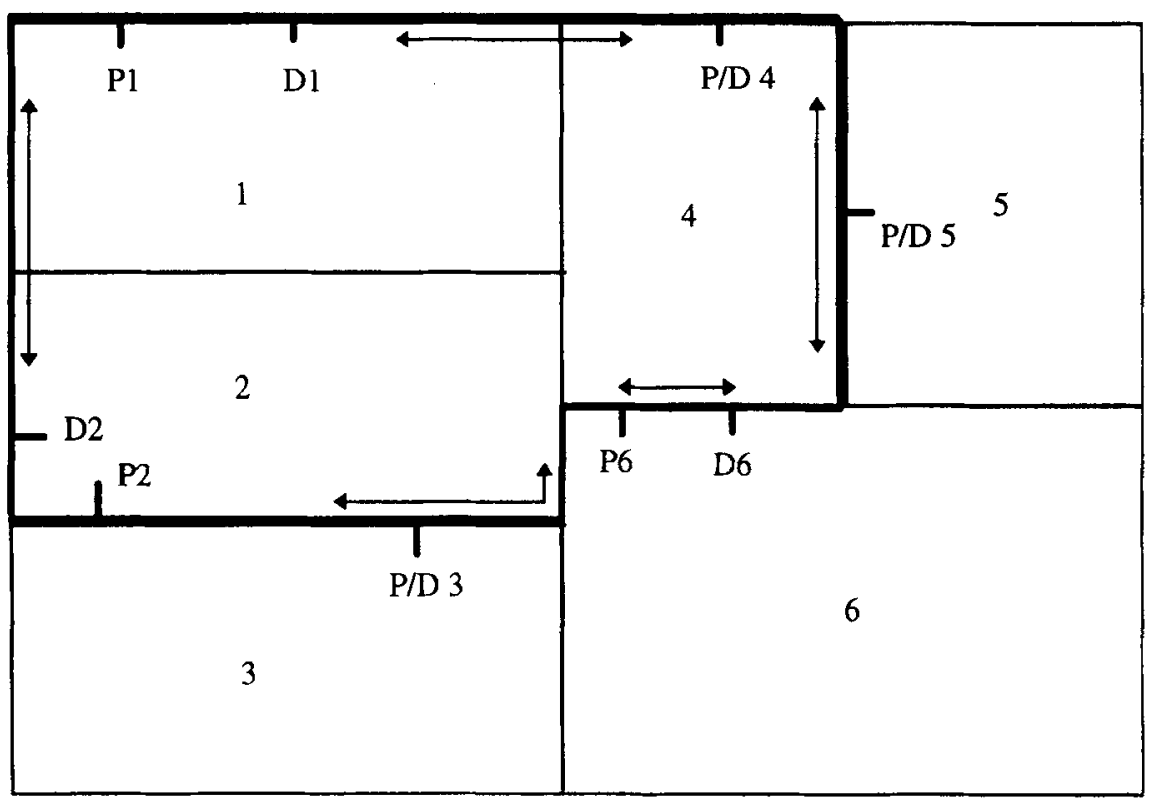

Figure 2. A schematic showing a single loop flowpath for bidirectional AGVs. 
the loop. Dominance rules are used to eliminate inferior loops and the optimal loop is decided based on a set of rules optimizing the desired performance criteria. Sinreich \& Tanchoco (1991) also developed other heuristic-based and rule-based methods to solve the $\mathrm{P} / \mathrm{D}$ point location and optimal single loop layout problem. They developed a centroid projection method which considered both inter-departmental and intra-departmental flows (Sinreich \& Tanchoco 1991). A genetic algorithm based method was developed by Banerjee \& Zhou (1995) which designed the facility layout for a single loop-based material flow network.

The loop layout design was formulated to ease the problem of designing the facility layout and the material-handling system. The wide application of such a layout also helped in increased research in this area. The loop layout consists of machines being arranged in a loop so as to facilitate material handling. In these problems, the material-handling system is assumed to be known and in most cases is either a unidirectional AGV or a conveyor. The problem then reduces to that of a single row layout problem with certain added constraints that machines may not be placed near the edges. Most solution techniques developed to solve these problems are either heuristic-based or rule-based methods.

A concept which simplifies the material handling system design even further and makes the control aspects of an AGV somewhat easier is the tandem layout. Developing a tandem layout involves grouping machines into cells and having a single loop AGV for each cell. Material transfer stations aid in transferring material from one cell to another. Bozer \& Srinivasan (1991) first discussed the concept of a tandem layout. They also developed a strategy for partitioning the shop floor into appropriate cells and developed a facility layout. The tandem layout assumes that each cell is serviced by a single unidirectional AGV. This design increases the chance of the entire production line being disrupted if any of the AGVs breaks down. Performance evaluation of a tandem layout versus the conventional AGV system has been done using petri-net models and simulation. The studies conclude that a tandem layout, under normal operating conditions, performs just as efficiently as a traditional layout and is also easier from a control perspective. Wang \& Hafeez (1994) proposed a terminal-based AGV system, where the AGVs are located in a terminal and on receiving a signal, the first available AGV goes to the pickup station along a preassigned path and then proceeds to the dropoff point. On completion of the task, the AGV returns to the main terminal. Variations of the terminal based AGV system were developed by Johnson \& Brandeau (1995). They used the principles of queuing network theory to evaluate their system.

Apart from the different types of layouts and flowpaths discussed above, the area of AGV flowpath design also considered the travel direction as an important parameter. Most studies assumed that the travel direction of the AGV was unidirectional, i.e. it could travel in one direction only. Egbelu \& Tanchoco (1986) conducted one of the earliest studies on the merits and demerits of using bi-directional travel as opposed to unidirectional travel. The problem of conflict routing and collision avoidance is more acute in the case of bidirectional AGVs. The solution methods used to solve this problem include techniques such as column generation (Krishnamurthy et al 1993), simulation (Faraji \& Batta 1994), graph theoretic approaches (Dowsland \& Greaves (1994)) and expert systems (Dhiouib \& Kadi (1994). The scheduling of AGVs has also been studied widely by researchers (Ulsoy \& Bilge 1993; Blazewicz et al 1994). The different scheduling rules, their relationship with 
the routing problem and the effect of these on the overall operation of the manufacturing system has been researched using techniques such as simulation and queuing theory.

\section{Integrated design process}

In the current literature, the most common assumptions made when solving the flowpath problem are that the layout is already given and that the $\mathrm{P} / \mathrm{D}$ points are already determined. The papers that deal with the loop layout problem assume that the material handling system has already been designed and then solve the layout problem. The tandem layout structure simplifies the flowpath problem, but relatively more AGVs are needed for a tandem layout than for a conventional layout and therefore it becomes a somewhat expensive proposition. Also, a breakdown of one of the vehicles in the system could bring the entire production to a halt.

The current manufacturing design process involves a sequential process where the initial stage involves process selection and equipment selection. This is followed by the layout design phase. Once the layout has been decided, the $\mathrm{P} / \mathrm{D}$ points are selected for this layout and then a material handling system is designed to minimize total travel time for the given layout and $\mathrm{P} / \mathrm{D}$ point locations. In such a case, the system that is designed may not be optimal overall although each phase in itself might be optimal. In other words, the AGV flowpath designed is optimal for the given layout, but the combined layout and flowpath may not be globally optimal. In order to overcome this, a model which simultaneously solves the flowpath and the layout must be developed. However, this combined problem is known to be NP-complete (Banerjee \& Zhou 1995) and solving such a model may not be possible.

The area of integrated design has been tackled by a few researchers. Chajjed et al (1992) solved the problem of identifying the P/D points and developed a free-flow materialhandling, network assuming the block layout was already known. Wu \& Egbelu (1994) tackled the problem of concurrently determining the layout and material-handling design by using a multistage approach. They use a loop-layout model and solve the problem of locating the cells within the loop. In this case the material-handling flowpath design problem is a trivial problem which translates into determining the $P / D$ points and layout along a loop. Palliyil \& Goetschalckx (1996) used a dual simplex-based approach to solve the problem of determining the aisles and load stations for an aisle-based materialhandling system. They assume that the layout is already known. Other works which tackle the problem of integrating two aspects of a manufacturing design problem include the combined layout and P/D point location problem (Heragu 1990), flowpath design and load size determination (Egbelu 1990) and equipment selection in conjunction with the load size determination (Noble et al 1994).

Integrated design problems are part of the current area of research which is being widely pursued. Heragu and Rajagopalan (1996) present a framework for developing a nearoptimal-solution to the manufacturing system design problem (figure 3). The framework involves a multi-stage solution procedure. The proposed strategy is a three-stage methodology that should result in an optimal or good solution depending on the size of the problem and the complexity involved. The first stage involves solving the layout problem using 


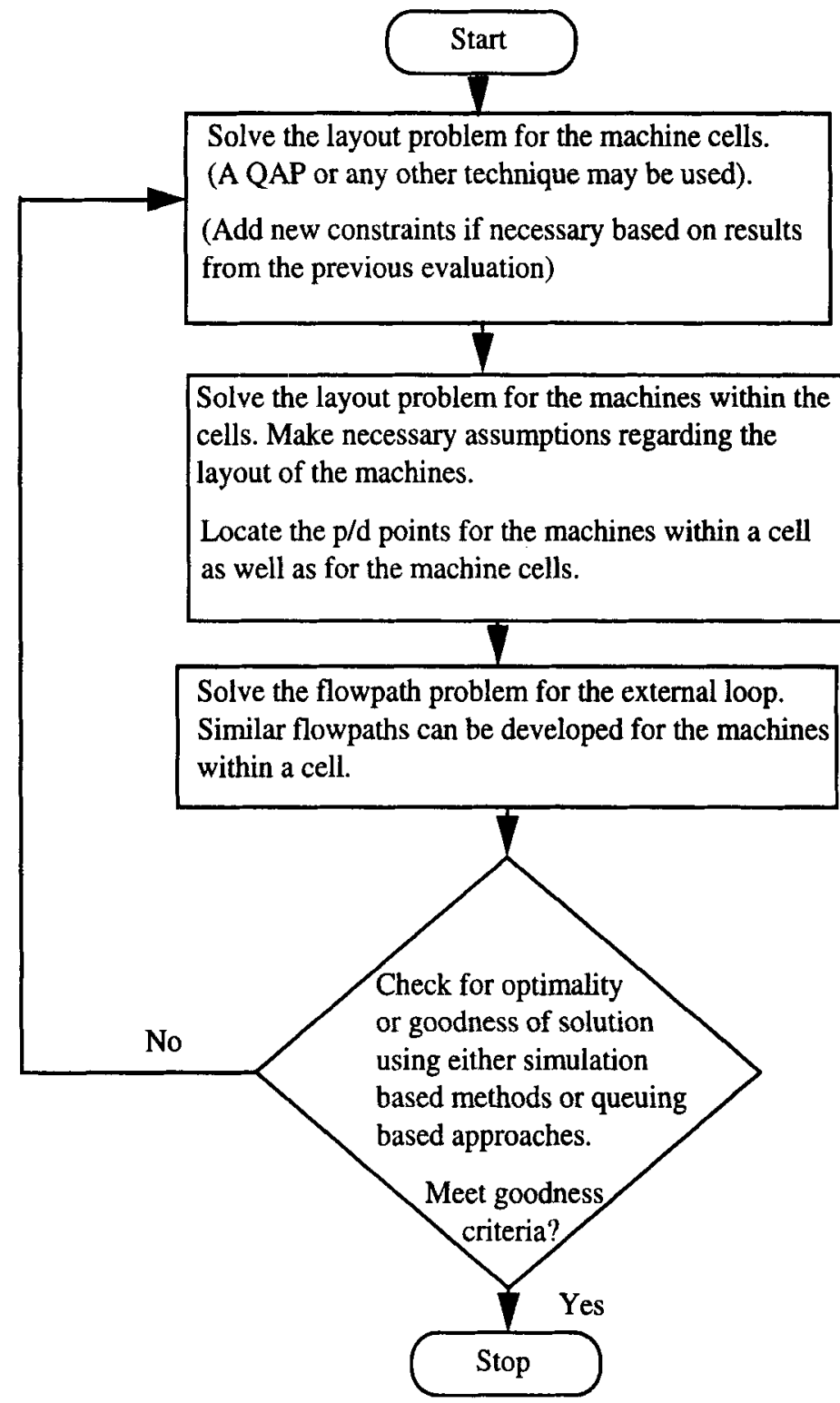

Figure 3. A flowchart describing the methodology used for the integrated design process.

the principles of cellular manufacturing system. The machines are grouped into cells and both the machine layout within a cell and the layout of the cells are decided. The materialhandling system for intra-cell material flow is decided based on the machines inside the cell and the operations being performed (figure 4). The P/D points for the cells are also determined.

The layout and the P/D point location can be combined if necessary by using models similar to those developed by Chajjed et al (1992). The second stage involves solving the flowpath problem for the cells based on the layout and the $P / D$ points developed. The next stage which is the most important stage in this process involves evaluating the performance 


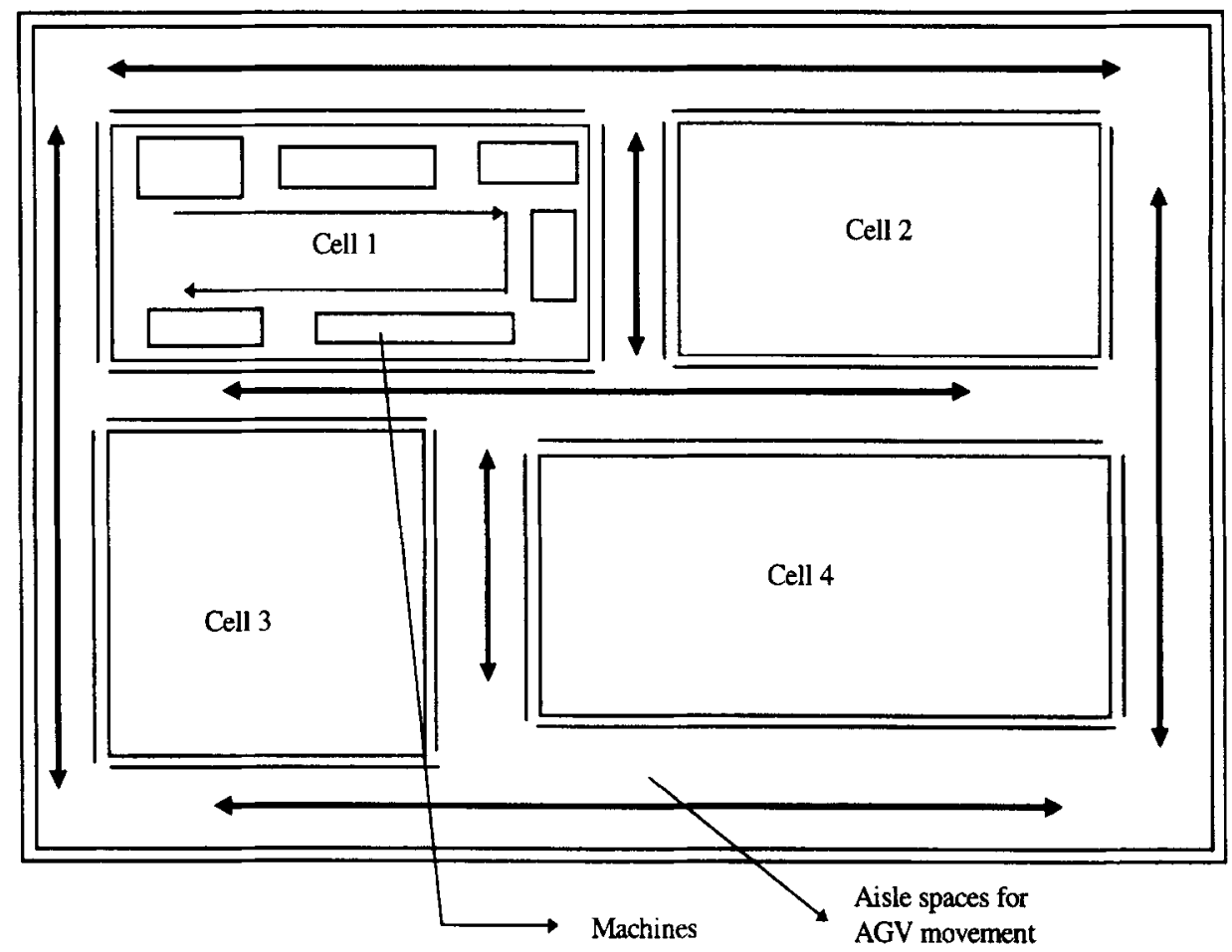

Figure 4. Schematic to show inter cell and intra cell material handling movement.

of the manufacturing system developed based on a predefined set of criteria. A feedback loop is required to ensure that the results obtained from the third stage are communicated to the first stage. The layout is then suitably altered and the process continues until all the criteria are met. The third stage which calculates the "goodness" of a solution consists of either a queuing-based model or a simulation model.

\section{Problem formulation}

In the case of bi-directional AGVs (where the AGVs can travel in both directions), the flowpath design problem can be formulated as an undirected graph network problem. The $P / D$ points are treated as nodes and the possible flowpaths connecting two $P / D$ points are modelled as arcs. The problem of developing a flowpath is now equivalent to finding the shortest path between any two nodes. The assumptions made in this analysis are:

(1) aisle spaces are known and AGV guides are laid along the aisles;

(2) material transfer rate ( or the from - to matrix) is known;

(3) number of AGVs required is already known.

The objective function of the problem can be changed to minimizing the total guidewire length that is to be laid and the problem can be solved as a minimum spanning tree problem. However, this approach assumes that the $\mathrm{P} / \mathrm{D}$ points are already known. In order to solve the $P / D$ point location and the flowpath problem concurrently, one must assume that the 
$\mathrm{P} / \mathrm{D}$ points are not known. This results in a situation where travel distance between any two nodes is stochastic and the resulting problem is one of stochastic single period network flow.

Every single point along the edge of a cell is a feasible $P / D$ point and therefore in order to determine the optimal or the best $P / D$ points all the points would have to be investigated. This results in a problem with infinite potential points making the problem intractable. For the purpose of this analysis, we will assume that both the pick-up and drop-off points for a given cell are at the same location. This assumption can be relaxed if necessary without increasing the complexity of the problem.

The large continuous problem can be reduced by considering discrete points that represent all the good solution points that exist. In selecting these scenarios, we must also ensure that we do not overlook a "good" or optimal P/D point. A few sample points are selected for each cell such that the maximum deviation from an optimal solution is reduced. The points selected for any cell are the extreme points, points of intersection with other cells, the centre of each side. Although these points may not be representative of the optimal solution to the problem, they will ensure that a good solution is obtained quickly. Hence, for any cell we only consider these 3 sets of points along each edge. In practice, a P/D point is never located at an edge and therefore the $P / D$ points are assumed to be located a small distance ' $\alpha$ ' away from the edge, where $\alpha=(($ length of $\mathrm{P} / \mathrm{D}$ station $) / 2)+\epsilon$ where $\epsilon$ is a small value. This limits the number of scenarios we need to consider to a maximum of 17 for each cell. This can be further reduced by using dominance rules.

The algorithm developed by Chajjed et al (1992) also helps in selecting P/D points and a flowpath for bi-directional AGVs. However, they assume a rectilinear distance matrix which is valid only in case all the $P / D$ points are situated at extreme points and are of equal sizes. In case of a layout with unequal machines and where the $\mathrm{P} / \mathrm{D}$ points are not situated at the extreme points of an edge, then their model can underestimate the actual travel distance by as much as the length of the largest side of a cell. For the case of large cells and a large number of trips, this underestimation adds up and results in a significantly lower travel distance than the actual distance. Kim \& Klein (1996) also developed an optimal algorithm to develop the $\mathrm{P} / \mathrm{D}$ points for an AGV system. They prove that the optimal $\mathrm{P} / \mathrm{D}$ point will always lie at the extreme end of a cell. However, their optimal algorithm and proof is valid only for the case where all the cells or machines are of equal size.

The problem of concurrently determining the $\mathrm{P} / \mathrm{D}$ points and flowpath in case of bidirectional AGVs can be formulated as a $k$ shortest path network flow problem. In case of small or medium-sized problems, any existing network flow algorithm such as Floyd's algorithm can be used for finding all shortest pairs (Ahuja et al 1993). In this case it is assumed that there exist no arcs between the nodes in the same cell to ensure that no more than one node is selected from each cell.

\section{Conclusions}

This paper presents an outline of the trends seen in layout and material-handling flowpath design research. It can be seen that the current trend is to try to integrate the different aspects of the manufacturing system design problem. The trend has also been to move 
towards more practical ways of tackling these problems and solving them quickly. The research focus is becoming more application based and several problems faced in the implementation stage are considered in the design stage itself. The manufacturing system design is now being considered as a whole instead of splitting it into various sub-problems. Although the entire problem being solved at once may not be feasible, a greater effort is being made to model the entire system or a set of subsystems. This paper also presents an idea for solving the $\mathrm{P} / \mathrm{D}$ point location and material-handling flowpath problem efficiently and quickly.

\section{References}

Ahuja R K, Magnanti T L, Orlin J B 1993 Network flows - theory, algorithms and applications (Englewood Cliffs, NJ: Prentice Hall)

Banerjee P, Zhou Y 1995 Facilities layout design optimization with single loop material flow path configuration. Int. J. Product. Res. 33: 183-203

Blazewicz J, Burkard R E, Finke G, Woeginges G J 1994 Vehicle scheduling in two-cycle flexible manufacturing systems. Math. Comput. Model. 20(2): 19-31

Bozer Y A, Srinivasan M M 1991 Tandem configurations for automated guided vehicle systems and the analysis of single-vehicle loops. IIE Trans. 23: 72-82

Chajjed D, Montreuil B, Lowe T J 1992 Flow network design for manufacturing systems layout. Eur. J. Oper. Res. 57: 145-161

Chen J 1995 Cellular manufacturing system design: optimal solution of large scale real world problems. Doctoral dissertation (unpublished), Rensselaer Polytechnic Institute, Troy NY

Dhouib K, Daoud A K 1994 Expert system for AGV managing in bidirectional networks: KADS methodology based approach. Int. J. Product. Econ. 33: 31-43

Dowsland K A, Greaves A M 1994 Collision avoidance in bidirectional AGV systems. J. Oper. Res. Soc. 45: 817-826

Egbelu P J 1990 Machining and material flow system design for minimum cost production. Int. J. Product. Res. 28: 353-368

Egbelu P J, Tanchoco J M A 1986 Potentials for bi-directional guide path for automated guided vehicle based systems. Int. J. Product. Res. 24: 1075-1097

Faraji M, Batta R 1994 Forming cells to eliminate vehicle interference and system locking in an AGVS. Int. J. Product. Res. 32

Hassan M M D 1994 Machine layout problem in modern manufacturing facilities. Int. J. Product. Res. 32: 2559-2584

Heragu S S 1990 Modelling the machine layout problem. Comput. Ind. Engg. 19: 294-298

Heragu S S 1992 Recent models and techniques for solving the layout problem. Eur. J. Oper. Res. 57: $136-144$

Heragu S S 1994 Group technology and cellular manufacturing. IEEE Trans. Syst., Man Cybern. 24: $203-215$

Heragu S S 1997 Facilities design (Boston, MA: PWS Publishing Company)

Heragu S S, Kusiak A 1991 Efficient models for the facility layout problem. Eur. J. Oper. Res. 53: $1-13$

Heragu S S, Rajagopalan S 1996 A literature survey of the AGV flowpath design problem. DSES Technical Report \# 37-96-446, Rensselaer Polytechnic Institute, Troy, NY

Johnson M E, Brandeau M L 1995 Designing multiple-load automated guided vehicle systems for delivering material from a central depot. J. Engg. Ind., Trans. ASME 117: 33-41 
Kim J, Klein C M 1996 Location of departmental pickup and delivery points for an AGV system. Int. J. Product. Res. 34: 407-420

Kouvelis P, Guitierrez G J, Chiang W C 1992 Heuristic unidirectional flowpath design approaches for automated guided vehicle systems. Int. J. Product. Res. 30: 1327-1351

Krishnamurthy N N, Batta R, Karwan M H 1993 Developing conflict free routes for automated guided vehicles. Oper. Res. 41: 1077-1090

Kusiak A, Heragu S S 1987 The facility layout problem. Eur. J. Oper. Res. 29: 229-251

Maxwell W L, Muckstadt J A 1982 Design of automated guided vehicle systems. IIE Trans. 14: 114-124

Noble J S, Klein C M, Midha A 1994 Integrated analysis of material flow systems. Proceedings of the 1994 International Mechanical Engineering Congress and Exposition, MHD 2, pp 33-38

Palliyil G, Goetschalckx M 1996 A comprehensive model for the concurrent determination of aisles and load stations for aisle based material handling systems. Working paper, School of Industrial and Systems Engineering, Georgia Institute of Technology

Peters B A, Smith J S, Venkatesh S 1995 A control classification of automated guided vehicle systems. Int. J. Ind. Engg. (accepted)

Sahni S, Gonzalez T 1976 P-complete approximation problem. J. Assoc. Comput. Mach. 23: $555-565$

Sinreich D 1996 Network design models for discrete material flow systems: A literature review. Int. J. Adv. Manuf. Technol. 10: 277-291

Sinreich D, Tanchoco J M A 1991 The centroid projection method for locating pick-up and delivery stations in single-loop AGV systems. J. Manuf. Syst. 11: 297-307

Sinreich D, Tanchoco J M A 1993 Solution methods for the mathematical models of single loop AGV systems. Int. J. Product. Res. 31: 705-725

Tanchoco J M A, Sinreich D 1992 OSL - optimal single loop guide paths for AGVS. Int. J. Product. Res. 30: 665-681

Ulsoy G, Bilge U 1993 Simultaneous scheduling of machines and automated guided vehicles. Int. J. Product. Res. 31: 2857-2873

Usher J S, Evans G W, Wilhelm M R 1988 AGV flow path design and load transfer point location. IIE International Industrial Engineering Conference Proceedings, pp 174-179

Wang H P B, Hafeez S A 1994 Performance evaluation of tandem and conventional AGV systems using generalized stochastic petri nets. Int. J. Product. Res. 32: 917-932

Wu C T, Egbelu P J 1994 Concurrent design of shop layout and material handling. Working paper, Department of Industrial and Management Systems Engineering, Pennsylvania State University 